\title{
Bronchogenic cyst mimicking an intracardiac mass: diagnosis by magnetic resonance imaging and treatment by needle aspiration
}

\author{
J W Roos-Hesselink, G T Verhoeven, J Stoker
}

\begin{abstract}
A 31 year old man was admitted because of dyspnoea during exercise and paroxysmal atrial fibrillation. A grade $2 / 6$ early diastolic murmur was heard along the lower left sternal border. The chest $x$ ray showed a large left atrium. Cross sectional echocardiography (fig 1) in several projections, supplemented by transesophageal echocardiography, however, showed no signs of mitral valve disease. Instead a round structure was seen projecting into the left atrium. Magnetic resonance imaging (MRI) (fig 2) showed a large $(5 \times 7 \times 9 \mathrm{~cm})$ mass with a smooth margin. The mass was compressing the left atrium, the oesophagus, and the large vessels. It had an intermediate signal intensity on $\mathrm{T} 1$ weighted spin-echo images and a high signal intensity on T2 weighted spin-echo images. These MRI findings and the site are specific for the diagnosis of bronchogenic cyst.
\end{abstract}

Others have reported on the diagnostic importance of MRI in patients with suspected atrial tumours. ${ }^{12}$ The location of the cyst and the compression of the left atrium explained the diastolic rumble, the arrhythmia, and the suspiMany different symptoms such as cough and dysphagia have been reported, but there are no other reported cases of bronchogenic cysts with cardiac symptoms mimicking mitral stenosis.

Because bronchogenic cysts are benign, needle aspiration is often sufficient. ${ }^{34}$ Most bronchogenic cysts remain empty after aspiration, although there is a report of a cyst recurring. ${ }^{5}$ In our patient needle aspiration of the cyst was

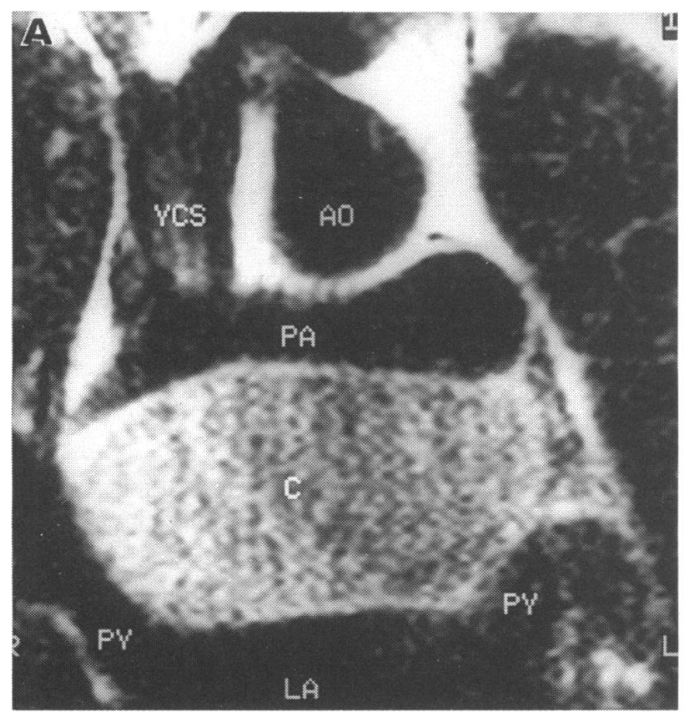
cion of a large left atrium on the chest $x$ ray.

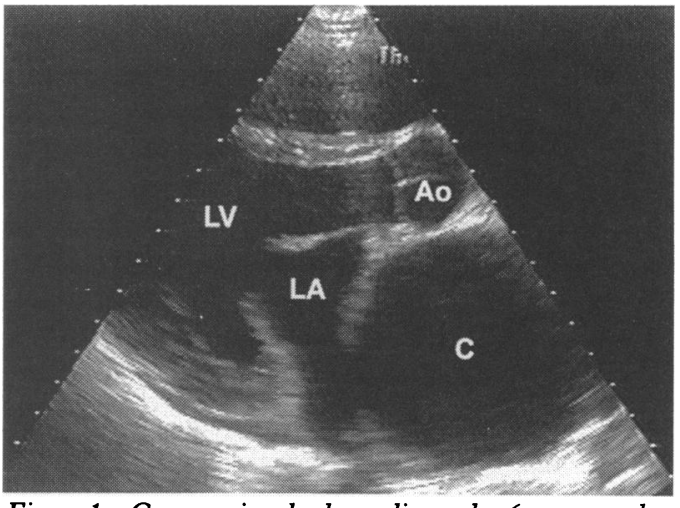

Figure 1 Cross sectional echocardiography (parasternal long-axis view) showing a round structure $(C$, cyst) in the left atrium (LA). LV, left ventricle; Ao, aorta.

performed through a bronchoscope with a rigid tube. Serous fluid $(100 \mathrm{ml})$ was aspirated and his symptoms disappeared. This patient has now remained free of symptoms for three years and repeated MRI scans have shown no recurrence of the cyst.

We thank Dr Mark Perlroth for his advice on this report.

1 Menegus MA, Greenberg MA, Spindola-Franco $H$, Fayemi A. Magnetic resonance imaging of suspected atrial tumors. Am Heart f 1992;123:1260-8.

2 Nakata H, Egashira K, Watanabe H, et al. MRI of bronchogenic cysts. $\mathcal{F}$ Comput Assist Tomogr 1993;17:267-70.

3 Kuhlman JE, Fishman EK, Pen Wang K, Zerhouni EA, Siegelman SS. Mediastinal cysts: diagnosis by CT and needle aspiration. $A f R$ 1988;150:75-8.

4 St-Georges R, Deslauriers J, Duranceau A, et al. Clinical spectrum of bronchogenic cysts of the mediastinum and lung in the adult. Ann Thorac Surg 1991;52:6-13.

5 Read CA, Moront M, Carangelo R, Holt RW, Richardson M. Recurrent bronchogenic cyst. Arch Surg 1991;126: 1306-8.

25 October 1995

Figure 2 Coronal T1weighted spin-echo MRI image. (A) Cyst (C)

located between the right pulmonary artery (PA) and left atrium (LA). (B) The same image after needle aspiration of the cyst. AO, aorta; VCS, superior vena cava;

$P V$, pulmonary vein.

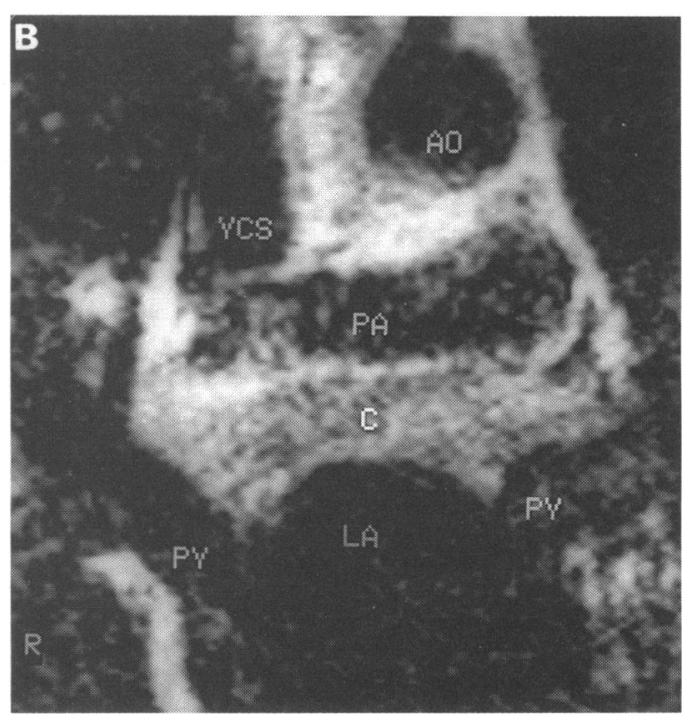

